\title{
Prevalence of anemia and its associated risk factors among urban school children of Chennai/ Tamilnadu
}

\author{
L. Kannan ${ }^{1, *}$, Praveena P. ${ }^{2}$ \\ ${ }^{1}$ Associate Professor, ${ }^{2}$ Assistant Professor, Dept. of Community Medicine, ${ }^{1}$ Sri Ramachandra Medical College \& Research \\ Institute, Porur, Chennai, ${ }^{2}$ Velammal Medical College, Madurai, Tamil Nadu, India
}

*Corresponding Author:

Email: kannansrmccommed@gmail.com

\begin{abstract}
Introduction: Anemia is one of the major public health problems among adolescence age group. In modern society intake of locally available of junk foods is common among different age groups which can lead up to other non communicable disorders in adults. On the other hand there is lot of low socioeconomic population living in urban area and their children are studying in urban schools that are exposed to commonly available neighboring foods around the school premises. These children when they don't have better performance in their academic career they become school dropouts and hunt for daily jobs for their survival. This study was done to find out the prevalence of clinical manifestation of anemia and associated factors among urban school children.

Materials and Methods: a cross sectional study design done on urban school children in saligramam south Chennai from 20152017.

Results: Prevalence of anemia was found to be 53.4\% (95\% CI 48.4-58.3). Males students were found to more $62.8 \%$ compared to female students $37.2 \%$. In terms of grading of anemia mild $130(33.3 \%)$ moderate $64(16.4 \%)$ and severe $14(3.6 \%)$ respectively and remaining were found to be normal. In this study all student in the government schools were from low socio economic background. a higher prevalence of anemia among the students who had open air defecation, not wearing regular foot wares and not maintaining regular hand washing and who have a habit of taking regular food from the locally available shops and overweight individuals. On clinical examination of the study participants of 390 individuals 204(52.3) revealed pallor of conjunctiva, tongue and nail bed. Most of the children had 254 (65.1) individuals had either of the clinical manifestation of anemia.

Conclusion: A higher prevalence of anemia has been found in this study among school children and their associated factors like open air defecation, regular frequent intake of outside foods and improper hand washing and underweight hence there should be periodic health examination and appropriate health education and health awareness has to sensitized to these individuals.
\end{abstract}

Keywords: Urban school students, Anemia.

\section{Introduction}

It was pronounced by World Health Organization that the hemoglobin concentration of blood is below the normal is termed as anemia. As a consequences of this may result in reducing the low oxygen carrying capacity of the RBC there by leading to many unexpected complications among the vulnerable group of adolescents. ${ }^{1}$

Adolescents are the vulnerable group for the development of nutritional disorder, they are prone for risk which can be born from the familial aspects and they may be carried away to their adults. The most common disorder among adolescence is nutritional anemia as a consequence of this may affect the child bearing age group from 15-49 years.

Most of the urban government school in Chennai from the low socio economic background have exposed to many risk factors for developing in to anaemia, due to lack of awareness, large family size, poor nutrition and open air defecation and associated menstrual disorders. $^{2}$

They are four time risk of developing anemia compared to developed countries

In India by $1970^{3}$ the government of India has launched a national nutritional programme for anemia i.e anemia prophylaxis program were it was targeted more for the vulnerable eligible couples of pregnant mothers and many agencies came forward for this program for strengthening the strategies they wanted to get adopted for control of anemia in rural area but there was least contribution in the urban school children according to the program. Though the urban government school children comes under the preview of urban primary care region, on every Thursdays there will be an school health activities but unfortunately there is a lack of services to rectify and halt the progress of disorder among these children. ${ }^{4}$

Adolescent school children are exposed to multiple dietary factors; they are eating most commonly available foods like rice porridge, snacks, locally available sweets from the neighboring shops and finally they land up in multiple factors of having worm infestations and there by leading to anemia. There are multiple factors can be predicted for the occurrence of the disease and clinical manifestation. ${ }^{5,6}$ In order to streamline the aspect of identification of various factors this study was undertaken To estimate the prevalence of clinical manifestation of anemia and associated riskfactors among adolescent urban school children in chennai.to find out the clinical manifestation of anemia 
and associated risk factors among adolescent urban school children in Chennai.

\section{Materials and Methods}

Study design: This is a selective population based cross sectional study conducted in a urban government school of southern part of Chennai. The nearby urban health care center is around $6 \mathrm{~km}$ from the school premises.

children between the age group of 10 years to 19 years. from 2015 to 2017 (2years).

Sampling method: simple random sampling by multi stage in selecting school hamlets nearly 5 government urban schools was randomly selected out of 18 schools as first stage of multi sampling of the available records form the officially available in the website. Among the 5 schools selected only one school was able to give us permission to conduct the study. The students of primary and secondary education were included in the study and a sum 390 students were selected by lottery method of the available registry as per the attendance record form the school after calculating the sample size for $55 \%$ as prevalence form the available studies ${ }^{5-8}$ and relative precision of 10 at $95 \%$ level and a sum of 390 individuals were selected as the study participants.

Development of interview schedule: An interview schedule was prepared based on the information obtained from various studies related to this topic and based on the observation during pretesting the interview schedule was modified for the final conduct of this study. The interview schedule included open and close ended questions for collecting information of socioeconomic and cultural factors, menstrual disorders, diet, personal hygiene and environmental sanitations like open air defecation etc. This was approved from Institutional Ethics Committee, sri Ramachandra university: IEC-NI/15/APR/46/20.

\section{Result}

A cross sectional study was conducted to find out the prevalence clinical manifestation of anemia among urban government school children.

The cross sectional study design was done to find out the prevalence clinical manifestation of anemia was done among urban government school children. The prevalence of anemia was found to be $53.4 \%$ (95\% CI 48.4-58.3). Majority of the males students $245(62.8 \%)$ were found to be anemic compared to female students $145(37.2 \%)$. In terms of grading of anemia mild 130(33.3) moderate 64(16.4) and severe 14(3.6) respectively and remaining were found to be normal. In this study all student in the government schools were from low socio economic background.

Table 1: Shows the distribution of anemia among different age groups students

\begin{tabular}{|c|c|c|c|c|c|}
\hline Age group & Anemia & $\begin{array}{c}\text { Prevalence } \\
\text { of anemia }\end{array}$ & $\begin{array}{l}\text { Odds } \\
\text { ratio }\end{array}$ & $95 \% \mathrm{CI}$ & p value \\
\hline $10-12$ & 27 & 64.3 & 2.48 & $1.09-5.70$ & \multirow{4}{*}{$\begin{array}{c}<0.05 \text { and } \\
\text { chi square } \\
\text { for trend } \\
=7.24\end{array}$} \\
\hline $12-14$ & 79 & 57.7 & 1.88 & $1.05-3.35$ & \\
\hline 14-16 & 65 & 52.8 & 1.54 & $1.06-2.02$ & \\
\hline$>16$ & 37 & 42 & 1.0 & $0.86-2.79$ & \\
\hline
\end{tabular}

It has been shown from the above table 1 the prevalence was higher in the age group 10-12 years compared to other group of students and there was significant positive association of increase in age group in relationship to anemia and is significant at 0.05 levels.

Table 2: Shows details of personal hygiene, environmental factors and anthropometric measurements based on percentile charts for boys and girls are shown $n=390$

\begin{tabular}{|c|c|c|c|c|c|}
\hline $\begin{array}{c}\text { Open air } \\
\text { defecation }\end{array}$ & $\begin{array}{l}\text { Anemic/non } \\
\text { anemic }\end{array}$ & Percentage & $\begin{array}{c}\text { Chi } \\
\text { square } \\
\text { value }\end{array}$ & $\begin{array}{l}\text { Odds } \\
\text { Ratio }\end{array}$ & P value \\
\hline Yes & $25 / 202$ & 58.2 & \multirow[t]{2}{*}{0.33} & \multirow[t]{2}{*}{1.21} & \multirow{2}{*}{$\begin{array}{c}0.56 \\
\text { (non-significant) }\end{array}$} \\
\hline no & $16 / 157$ & 41.8 & & & \\
\hline \multicolumn{6}{|l|}{$\begin{array}{l}\text { Regular } \\
\text { wearing of foot } \\
\text { wears }\end{array}$} \\
\hline yes & $189 / 127$ & 81 & \multirow[t]{2}{*}{0.82} & \multirow[t]{2}{*}{1.26} & \multirow{2}{*}{$\begin{array}{c}0.365 \\
\text { (non-significant) }\end{array}$} \\
\hline no & $40 / 34$ & 19 & & & \\
\hline \multicolumn{6}{|l|}{ Hand washing } \\
\hline yes & $29 / 185$ & 54.9 & \multirow[t]{2}{*}{17.90} & \multirow[t]{2}{*}{0.34} & \multirow{2}{*}{$\begin{array}{c}0.00023 \\
\text { (significant) }\end{array}$} \\
\hline no & $55 / 121$ & 45.1 & & & \\
\hline \multicolumn{6}{|l|}{ Anal itching } \\
\hline yes & $23 / 12$ & 9 & \multirow[t]{2}{*}{0.000} & \multirow[t]{2}{*}{1.00} & \multirow{2}{*}{$\begin{array}{c}0.99 \\
\text { (non-significant) }\end{array}$} \\
\hline no & $233 / 122$ & 91 & & & \\
\hline
\end{tabular}




\begin{tabular}{|l|c|c|c|c|c|}
\hline $\begin{array}{l}\text { Frequent intake } \\
\text { of locally } \\
\text { available foods }\end{array}$ & & & & & \\
\hline yes & $36 / 160$ & 50.3 & \multirow{2}{*}{14.83} & 3.74 & $\begin{array}{c}0.0001176 \\
\text { (significant) }\end{array}$ \\
\cline { 1 - 3 } no & $11 / 183$ & 49.7 & & & \\
\hline weight & $45 / 15$ & 15.4 & -- & 159.95 & $\begin{array}{c}0.000 \\
\text { (significant) }\end{array}$ \\
\cline { 1 - 3 } under weight & $22 / 276$ & 76.4 & & & \\
\hline normal & $2 / 30$ & 8.2 & & & \\
\hline over weight & & &
\end{tabular}

From the above table 2 showed a higher prevalence of anemia among the students who had open air defecation, not wearing regular foot wares and not maintaining regular hand washing and who have a habit of taking regular food from the locally available shops and overweight individuals.

On clinical examination of the study participants of 390 individuals 204(52.3) revealed all manifestations in pallor of conjunctiva, tongue and nail bed. Most of the children had 254 (65.1) individuals were found to be normal and over all anemic subjects were 208 had one or either of the manifestation of anemia. When compared with other associated factors in relationship to anemia it has been found in table 2 even though it has an positive association with open air defecation, wearing of foot wears and anal itching it was not statistically significant as a contributing factor for anemia but on the other hand there were highly significant factor with other factors like hand washing, frequent intake of locally available foods and weight has got an indirect relationship with positive association, by this we can conclude these factors may be the contributing for the clinical manifestation of anemia.

\section{Discussion}

From the available research studies the prevalence of anemia was ranging from $32-65 \%$. A study done in wayanad district found to be more $96.5 \%$ but in the present study there was lower prevalence compared to other studies and similar studies reported in Tamil nadu ${ }^{8}$ and Andra Pradesh ${ }^{7}$ as $58.4 \%$ and $77.3 \%$ the prevalence in Wayanad district prevalence of mild anaemia was $30.5 \%$, and that of severe was $10.1 \%$ that of moderate anaemia was $55.9 \% .^{10}$ Similar prevalence is reported by CMS Rawat et al. ${ }^{11}$ at Meerut. A higher prevalence was noted by J Rajaratnam et al. ${ }^{12}$ in Tamil Nadu. Toteja GS et $a l^{13}$ found $90.1 \%$ prevalence of anemia among adolescent girls from 16 districts of India, with $7.1 \%$ having severe anemia. In this study, a significant association of anemia was found with socioeconomic status, which may be due to the availability of high quality food with better socio-economic status. A significant association of the prevalence of anemia with educational status of parents reflects better awareness among literate mothers, as well as better socio-economic conditions. None of the subjects had severe anemia. Bulliyy et al. ${ }^{14}$ found $96.5 \%$ prevalence among non school going adolescent girls in three districts of Orissa, of which, $45.2 \%, 46.9 \%$, and $4.4 \%$ had mild, moderate, and severe anemia. They found significant association between $\mathrm{Hb}$ concentration and the educational level of girls, their parents' family income, and body mass index. ${ }^{15}$ Similar results were obtained in a study conducted among adolescent groups in Andhra Pradesh with prevalence of mild anaemia was $28.7 \%$, that of moderate anaemia $39.33 \%$ and that of severe anaemia $9.33 \% .{ }^{9}$ In the present study all were from the low socio economic background.

\section{Conclusion}

A higher prevalence of anemia has been found in this study among school children and their associated factors like open air defecation, regular frequent intake of outside foods and improper hand washing and underweight hence there should be periodic health examination and appropriate health education and health awareness has to sensitized to these individuals.

\section{References}

1. World Health Organization. Strategic directions for improving adolescent health in South-East Asia Region. 2011 [cited 2016 Jun 10]; Available from: http://apps. who.int/iris/handle/10665/205917.

2. Devi R, Jaysree TM, Felix AJW, Ethirajan N. Prevalence of anemia among children age 10 to 15 years in urban, Chidambaram. J Drug DiscovTher. 2014;2(22):67-70.

3. Aguayo VM, Paintal K, Singh G. The adolescent girls' anaemia control programme: a decade of programming experience to break the inter-generational cycle of malnutrition in India. Public Health Nutr. 2013;16(9):1667-76

4. Gupta A, Parashar A, Sharma D, Thakur A. Anemia among adolescent girls in Shimla hills of north India: Does BMI and onset of menarche have a role? Indian J Med Sci. 2012;66(5):126.

5. Raj A, Chopra AK. A study showing correlation between anaemia and common parasitological diseases among adolescent girls in villages of PHC Belkhera, Madhya Pradesh, India. Int J Community Med Public Health. 2016;3(1):373-79.

6. Aishwarya MV, ParitaGajjar DP, Raykundaliya RS, Patel VH, Neeta D. Prevalence of anemia and epidemiological correlates among school going adolescent boys of Vallabh Vidyanagar (Gujarat). Indian J Community Med. 2015;2014-5.

7. Biradar SS, Biradar SP, Alatagi AC, Wantamutte AS, Malur PR. Prevalence of anaemia among adolescent girls: a one year cross-sectional study. J Clin Diagn Res. 2012;6:372-77. 
8. Patil SV, Durgawale PM, Kakade SV, Dighe S. An assessment of interventional strategies for control of anemia among adolescent girls in an urban slum of Karad, Dist. Satara, Maharashtra. 2014 [cited 2016 Jun 9]; Available from: http://trafficlight.bitdefender.com/info?url=http\%3A//ajm s.alameenmedical. org/ArticlePDFs/5\%2520AJMS\%2520V7.N3.2014\%252 0p\%2520195-200. pdf\&language=en_US

9. Gupta A, Parashar A, Sharma D, Thakur A. Anemia among adolescent girls in Shimla hills of north India: Does BMI and onset of menarche have a role? Indian J Med Sci. 2012;66(5):126

10. Sachan B, Idris MZ, Singh A. Effect of sociodemographic characteristics on the prevalence of anemia among school going adolescent girls in Lucknow district, India. South East Asia J Public Health. 2013;2(1):8-12.

11. Rawat CMS, Garg SK, Singh JV, Bhatnagar M, Chopra $\mathrm{H}$, Bajai SK. Sociodemographic correlates of anemia among adolescent girls in rural district of Meerut. Indian J Community Med. 2001;26:173-5.

12. Rajaratnam J, Abel R, Asokan JS, Jonathan P. Prevalence of anemia among adolescent girls of rural Tamil Nadu. Indian Pediatr. 2000;37:532-6. [PubMed]

13. Toteja GS, Singh P, Dhillon BS, Saxena BN, Ahmed FU, Singh RP, et al. Prevalence of anaemia among pregnant women and adolescent girls in 16 districts of India. Food Nutr Bull. 2006;27:311-5. [PubMed]

14. Bulliyy G, Mallick G, Sethy GS, Kar SK. Haemoglobin status of non school going adolescent girls in three districts of Orissa, India. Int J Adolesc Med Health. 2007;19:395-406. [PubMed]

15. Khanduri U, Sharma A. Megaloblastic anaemia: Prevalence and causative factors. Natl Med J India. 2007;20:172-5. [PubMed] 